Article

\title{
Control of Sequential MTO Reactions through an MFI-Type Zeolite Membrane Contactor
}

\author{
Shusei Tanizume, Toshihiro Yoshimura, Katsunori Ishii and Mikihiro Nomura * \\ Department of Applied Chemistry, Shibaura Institute of Technology, 3-7-5 Toyosu, Koto-ku, Tokyo 135-8548, \\ Japan; ad15050@shibaura-it.ac.jp (S.T.); mc18037@shibaura-it.ac.jp (T.Y.); na19101@shibaura-it.ac.jp (K.I.) \\ * Correspondence: Lscathy@shibaura-it.ac.jp; Tel.: +81-35-859-8160
}

Received: 14 December 2019; Accepted: 6 February 2020; Published: 7 February 2020

\begin{abstract}
A membrane for controlling methanol-to-olefin (MTO) reactions was developed, which featured an MFI-type zeolite membrane $(\mathrm{Si} / \mathrm{Al}=25)$ that was synthesized on a porous $\alpha$-alumina substrate using a secondary growth method. Here, the $\mathrm{H}_{2} / \mathrm{SF}_{6}$ permeance ratios were between 150 and 450 . The methanol conversion rate was $70 \%$ with $38 \%$ ethylene selectivity and $28 \%$ propylene selectivity as determined using a cross-flow membrane contactor. In order to improve the olefin selectivity of the membrane, the MFI zeolite layer $(\mathrm{Si} / \mathrm{Al}=\infty)$ was coated on an MFI-type zeolite membrane $(\mathrm{Si} / \mathrm{Al}=25)$. Using this two-layered membrane system, the olefin selectivity value increased to $85 \%$; this was $19 \%$ higher than the value obtained during the single-layer membrane system.
\end{abstract}

Keywords: zeolite membrane; MFI-type zeolite; membrane contactor; MTO reaction; silicalite-1 coating; catalyst regeneration

\section{Introduction}

Year after year, the demand for lower olefins, such as ethylene and propylene, increases owing to their popularity as raw materials for various products, including fibers, plastics, and resins. To close this gap between demand and supply, faster, more efficient production processes must be developed and implemented. To this end, methanol-to-olefin (MTO) reactions are attracting great attention as a means to quickly produce lower olefins from easily sourced hydrocarbons, such as methane or ethane [1]. The MTO reaction is a sequential process that transitions all the way from methanol through dimethyl ether (DME), olefins, paraffins, and finally aromatics via a double-cycle mechanism that was proposed by Olsbye et al. [2].

Zeolites, such as SAPO-34 (Chabazite, CHA) and ZSM-5 (MFI), are used for various commercial applications, for example, as a catalyst for ion exchange reactions, for mesopore production via alkali treatment, and for dealumination via acid treatment [3-6]. MFI-type zeolites used as catalytic membranes are aluminosilicate crystals with pore dimensions of $5.6 \times 5.3 \AA$ and are typically used for methanol-to-gasoline reactions. However, Mohammad et al. reported that the ZSM- 5 catalyst in an MTO reaction was capable of $99.3 \%$ methanol conversion with $48.3 \%$ propylene selectivity over the course of $170 \mathrm{~h}$ under alkaline conditions [5].

Generally, a sequential reaction can be regulated by controlling the contact time between the reactants and the catalyst via the use of a membrane contactor. In cases where a fixed-bed catalytic reactor is used, it is difficult to precisely control the contact time due to diffusion processes in the environment around the catalyst. Thus, a high degree of selectivity for the intermediate products is needed in situations that require a thin catalytic membrane. Masuda et al. applied a catalytic membrane contactor using MFI-type zeolites to an MTO reaction [7] and found that the methanol conversion rate was $90 \%$ with an olefin selectivity value of $80 \%$. Tago et al. controlled the contact time of the catalyst with a higher degree of accuracy by inactivating the reaction on the surface of the ZSM- 5 
membrane, resulting in $85 \%$ olefin selectivity [8]. However, the effects of a cross-flow reactor were not discussed in that study. In order to commercialize these types of membrane contactors, cross-flow-type reactors should be further developed.

Numerous studies were conducted using MFI-type zeolite membranes [7-11]. Sugiyama et al. developed a new silica substrate that improved gas permeation from $3.0 \times 10^{-6} \mathrm{~mol} \cdot \mathrm{m}^{-2} \cdot \mathrm{s}^{-1} \cdot \mathrm{Pa}^{-1}$ for $\mathrm{N}_{2}$ permeance to $108 \times 10^{-6} \mathrm{~mol} \cdot \mathrm{m}^{-2} \cdot \mathrm{s}^{-1} \cdot \mathrm{Pa}^{-1}$ for $\mathrm{N}_{2} / \mathrm{SF}_{6}$ permeance [9]. Ueno et al. established the amount of seed crystal coating needed to improve the selective permeation of acetic acid ( $\mathrm{AcOH})$. An $\mathrm{AcOH} / \mathrm{H}_{2} \mathrm{O}$ separation factor of 33 with a total flux of $0.04 \mathrm{~kg} \cdot \mathrm{m}^{-2} \cdot \mathrm{h}^{-1}$ was observed for the membrane coated with $5 \mathrm{~g} \cdot \mathrm{m}^{-2}$ of seeds [10]. Zhou et al. synthesized MFI-type zeolite membranes with high ethanol selectively for the successful preparation of an extremely diluted solution $\left(\mathrm{H}_{2} \mathrm{O} / \mathrm{SiO}_{2}\right.$ ratio of 800) and tetra- $n$-propylammonium bromide (TPABr) as inexpensive structure-directing agents [11].

In this study, an MFI-type zeolite membrane contactor was developed using a cross-flow reactor. The effects of surface coating and the regeneration of the MFI-type zeolite membrane are discussed further.

\section{Materials and Methods}

\subsection{Preparation of the MFI-Type Zeolite Membrane}

The MFI-type zeolite membrane was prepared from an $\alpha$-alumina substrate (outer diameter: $10 \mathrm{~mm}$, length: $30 \mathrm{~mm}$ ) using a secondary growth method. Here, MFI-type zeolite seed crystals were prepared in accordance with the protocols from previous reports [11] and applied to the substrate via dip coating. For the synthetic gel, tetra- $n$-propylammonium bromide (TPABr, $98 \%$; FUJIFILM Wako Pure Chemical Corporation, Osaka, Japan), tetramethoxysilane (TMOS; Shin-Etsu Chemical Co., Ltd., Tokyo, Japan), sodium hydroxide ( $\mathrm{NaOH}, 97.0 \%$, zeolites; Kanto Chemical Co., Inc., Tokyo, Japan), sodium aluminate $\left(\mathrm{NaAlO}_{2}, \mathrm{Al} / \mathrm{NaOH}=0.81\right.$; FUJIFILM Wako Pure Chemical Corporation, Osaka, Japan), and pure water were used. The composition of the resulting gel was TMOS:TPABr:NaOH: $\mathrm{H}_{2} \mathrm{O}: \mathrm{NaAlO}_{2}$ $=$ 1:0.2:0.07:200:0.04 molar ratio. The resulting synthetic gel was stirred at room temperature for $1 \mathrm{~h}$, followed by hydrothermal synthesis at $180^{\circ} \mathrm{C}$ for $16 \mathrm{~h}$. Thereafter, it was calcined at $500^{\circ} \mathrm{C}$ for $15 \mathrm{~h}$.

A second layer was applied to suppress surface reactions in the membrane contactor. The composition of the synthetic gel was TMOS:TPABr:NaOH: $\mathrm{H}_{2} \mathrm{O}=1: 0.005: 0.05: 75$. The synthetic gel was stirred for $1 \mathrm{~h}$, followed by hydrothermal synthesis at $180^{\circ} \mathrm{C}$ for $24 \mathrm{~h}$ and calcination at $500^{\circ} \mathrm{C}$ for $15 \mathrm{~h}$. Ammonium chloride ( $\mathrm{NH}_{4} \mathrm{Cl}$; FUJIFILM Wako Pure Chemical Corporation, Osaka, Japan) was used for the ion exchange process for the conversion into the $\mathrm{H}^{+}$form. The membrane was then immersed in $1 \mathrm{M} \mathrm{NH}_{4} \mathrm{Cl}$ aqueous solution at $85^{\circ} \mathrm{C}$ for $3 \mathrm{~h}$. Thereafter, calcination occurred at $500{ }^{\circ} \mathrm{C}$ for $3 \mathrm{~h}$.

\subsection{Characterization}

For the characterization of the MFI-type zeolite membrane, an X-ray diffractometer (XRD; SmartLab, Rigaku, Tokyo, Japan) and a scanning electron microscope (SEM, VE8800; Keyence, Osaka, Japan) were used. Energy-dispersive X-ray spectroscopy (EDS, JSM-7610, JEOL, Tokyo, Japan) was employed for elemental analysis. The single-gas permeances of $\mathrm{H}_{2}, \mathrm{~N}_{2}$, and $\mathrm{SF}_{6}$ were measured using a bubble flowmeter at room temperature.

The gas permeance $P_{i}\left(\mathrm{~mol} \cdot \mathrm{m}^{-2} \cdot \mathrm{s}^{-1} \cdot \mathrm{Pa}^{-1}\right)$ was calculated using Equation (1), where $n_{i} / t\left(\mathrm{~mol} \cdot \mathrm{s}^{-1}\right)$ denotes the molecular permeation rate, $A\left(\mathrm{~m}^{2}\right)$ is, the membrane area, and $\Delta p(\mathrm{~Pa})$ is the pressure difference between the membrane feed side and the permeate side. As presented in Equation (2), membrane selectivity was evaluated using the permeance ratio $\alpha_{i j}(-)$.

$$
\begin{gathered}
P_{\mathrm{i}}=\frac{n_{\mathrm{i}}}{t \cdot A \cdot \Delta p} . \\
\alpha_{\mathrm{ij}}=P_{\mathrm{i}} / P_{\mathrm{j}} .
\end{gathered}
$$




\subsection{The MTO Reaction}

Figure 1 presents in detail the experimental apparatus used for the MTO reaction. Here, methanol was evaporated in the bubbler and supplied to the outside (supply side) of the membrane using $\mathrm{N}_{2}$ as the carrier gas. In addition, $\mathrm{N}_{2}$ was supplied as the sweep gas to the inside (permeate side) of the membrane to "sweep" molecules that permeated from the membrane supply side to the permeate side. The reaction was continued for $5 \mathrm{~h}$ at $400{ }^{\circ} \mathrm{C}$. The carrier gas flow rate was $9.3 \mathrm{~mL} \cdot \mathrm{min}^{-1}$, the sweep gas flow rate was $32 \mathrm{~mL} / \mathrm{min}$, and the supplied methanol vapor concentration was $0.27 \mathrm{~mol} \cdot \mathrm{L}^{-1}$. The product composition obtained from the permeate side was analyzed using gas chromatography (GC-2014, Shimadzu, Japan). Moreover, the conversion $\left(\mathrm{X}_{\mathrm{MeOH}}\right)$ rate and the selectivity $\left(\mathrm{S}_{\mathrm{C} x \mathrm{Hy}}\right)$ were calculated using the following formulas:

$$
\begin{gathered}
\mathrm{X}_{\mathrm{MeOH}}=\frac{(\text { Amount of carbon derived from product })}{(\text { Total amount of permeated carbon })}, \\
S_{\mathrm{C}_{x} H_{y}}=\frac{\left(\text { The amount of carbon of the target substance }\left(C_{x} H_{y}\right)\right)}{(\text { Amount of carbon derived from product })} .
\end{gathered}
$$

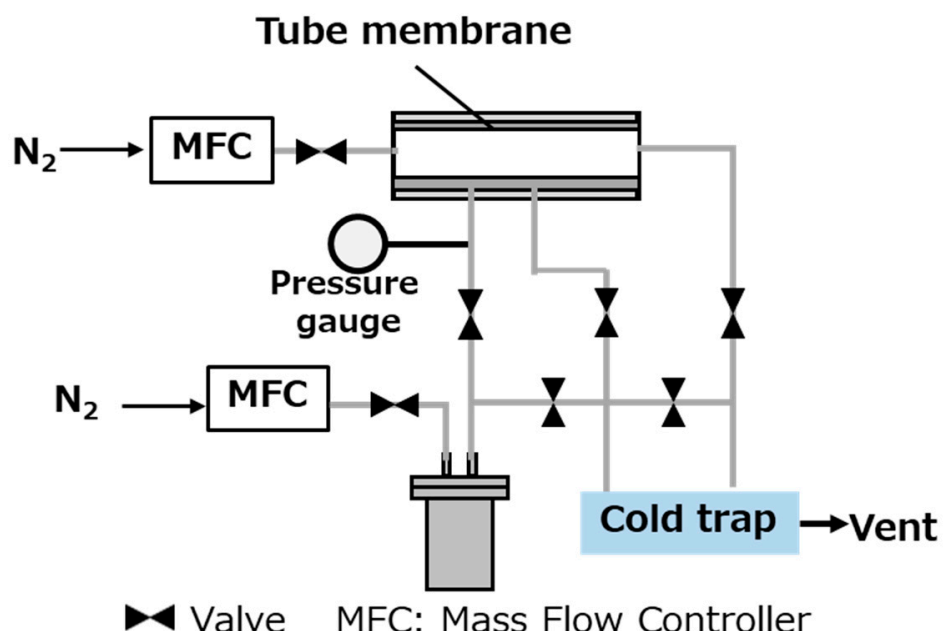

Figure 1. Schematic for the membrane contactor, including a diagram for the membrane module.

\subsection{Regeneration of the Catalyst via $\mathrm{O}_{3}$ Treatment}

The catalytic property of the membrane was regenerated by heating under ozone at $100{ }^{\circ} \mathrm{C}$ for $4 \mathrm{~h}$, following the protocol established in a previous study [12]. $\mathrm{O}_{3}$ was supplied to the outer side of the membrane at a flow rate of $200 \mathrm{~mL} \cdot \mathrm{min}^{-1}$.

\section{Results and Discussion}

\subsection{Characterization}

Figure 2 presents the SEM images of the MFI-type zeolite membrane's surface on an $\alpha$-alumina substrate. In Figure 2a, randomly oriented coffin-like crystals of about 6 to $9 \mu \mathrm{m}$ in size can be observed (first layer), whereas, in Figure 2b, terraced structures were noted on the surface crystals of the MFI-type zeolite membrane (second layer). Even though the crystal sizes were similar on both surfaces, the crystal growth rate varied depending on the $\mathrm{Si} / \mathrm{Al}$ ratio of the parent gel. Without the addition of $\mathrm{Al}$ to the parent gel, the prevailing reaction conditions induced much slower crystallization of the second layer. No cracks or pinholes were observed on the surface of the membrane. 


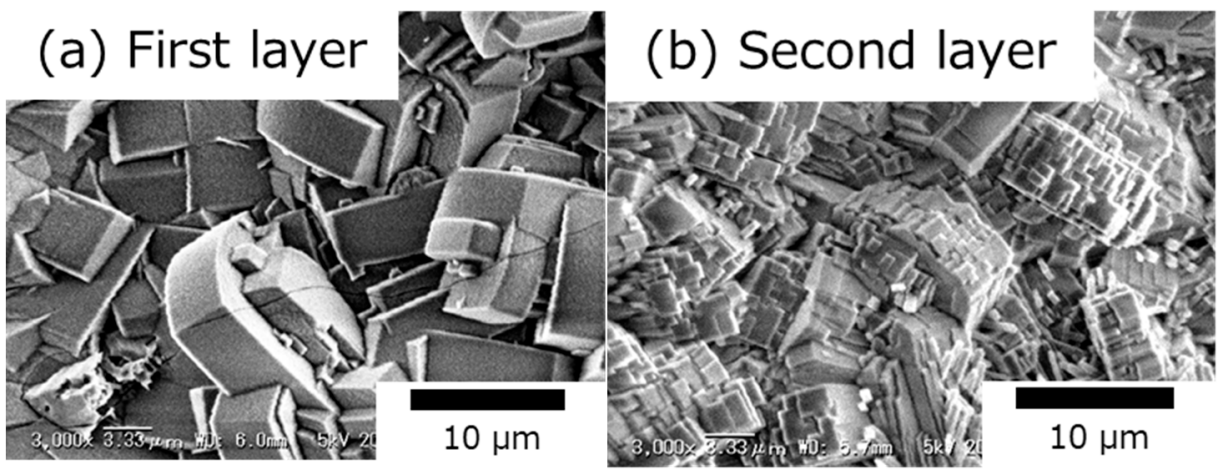

Figure 2. SEM images of the membrane's surface of the (a) first layer and (b) second layer.

Figure 3 presents the XRD patterns of the prepared MFI. Here, the peaks associated with the MFI structure were observed at $7.92^{\circ}$ (diffractive surface (011)), $8.88^{\circ}$ (diffracted surface (020)), $14.76^{\circ}$ (diffracted surface (031)), and $23.08^{\circ}$ (diffracted surface (051)). The peak at around $35^{\circ}$ was attributed to the alumina substrate. No diffraction patterns were observed, except for those linked to MFI and the alumina substrate, which indicated that pure MFI-type zeolite layers were obtained in both parent gels for the first and second layers. In addition, a more prominent peak was confirmed at around $7.9^{\circ}$ for the second layer. The intensity ratio, which is defined as the first layer/two-layered membrane (1:1.1), was considered to be proportional to the membrane's thickness.

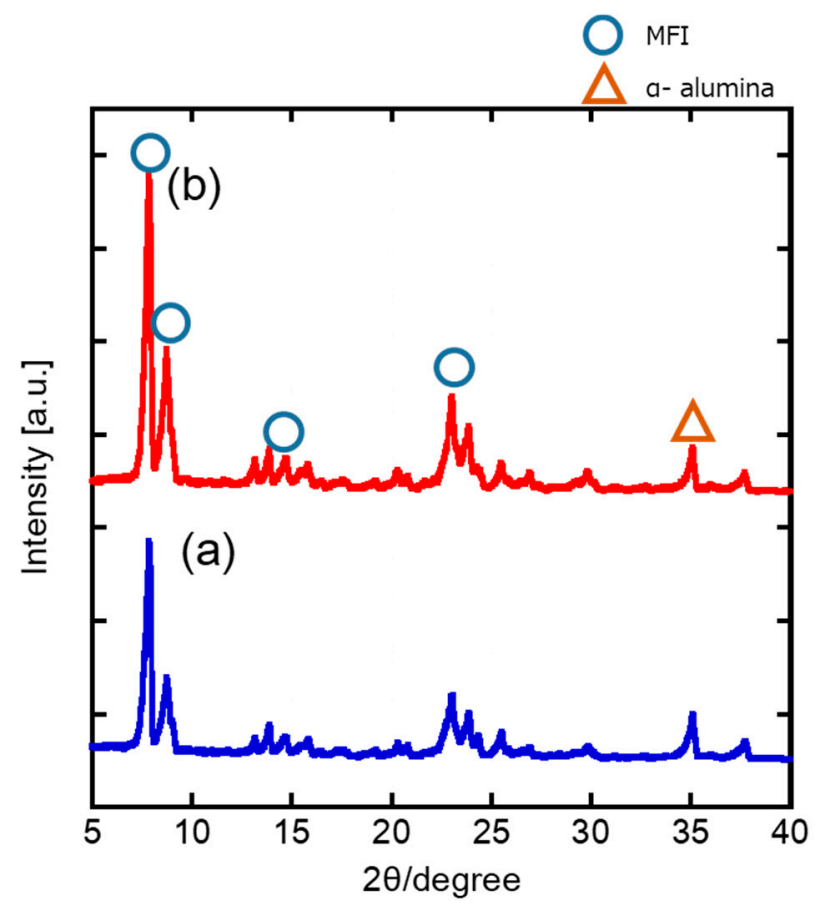

Figure 3. X-ray diffraction (XRD) patterns of the MFI-type zeolite membranes: (a) first layer; (b) two-layered membrane.

Figure 4 presents the SEM image of the membrane's cross-section and the concentration distribution of $\mathrm{Al}$ and $\mathrm{Si}$ as determined using EDS line analysis. Figure 4a presents an $\mathrm{Si} / \mathrm{Al}$ ratio of 25 for the single layer, whereas Figure $4 \mathrm{~b}$ presents the two-layered membrane with the second layer on the first layer. The thickness of the single-layer membrane $(\mathrm{Si} / \mathrm{Al}=25)$ was $10 \mu \mathrm{m}$. For line analysis, measurements were performed in the direction of the zeolite layer, with $0 \mu \mathrm{m}$ being assigned to the alumina substrate. The average $\mathrm{Si} / \mathrm{Al}$ ratio of the single-layer membrane was 17 . Since the molar ratio of $\mathrm{Si} / \mathrm{Al}$ in the parent gel was 25 , it was possible that Al originating from the alumina substrate was introduced into 
the zeolite structure. Si existed only in the zeolite layer; thus, the membrane thickness measured from the line analysis was $8.4 \mu \mathrm{m}$. This was in agreement with the results of the SEM cross-section, and the same level of thickness could also be observed in the left SEM cross-sectional image. On the other hand, the thickness of the first and second layers was 8.0 and $7.2 \mu \mathrm{m}$, respectively, according to the EDS analysis of the two-layered membrane. The XRD patterns indicate that the MFI diffraction intensity of the two-layered membrane was smaller than that of the single-layer membrane. However, when compared with the diffraction intensity of the alumina substrate (Figure 3), the two-layered MFI-type zeolite membrane was thicker than the single-layer membrane, as denoted by the small peak observed for the two-layered membrane. This difference in the MFI diffraction intensities may be due to the crystallinity of the two-layered zeolite (Figure 2). In addition, the average Si/Al ratio of the second layer in the membrane cross-section was 18, which was slightly higher than the average $\mathrm{Si} / \mathrm{Al} \mathrm{ratio}$ of the first layer. Since the gel medium used for synthesis did not contain $\mathrm{Al}$ in the coating layer, $\mathrm{Al}$ was introduced into the MFI-type zeolite layer via the elution of the alumina substrate. However, since the average $\mathrm{Si} / \mathrm{Al}$ ratio of the first layer in the membrane cross-section was 16 , it can be said that the influence exerted by the $\mathrm{Al}$ atoms obtained from the elution of the alumina substrate was large.
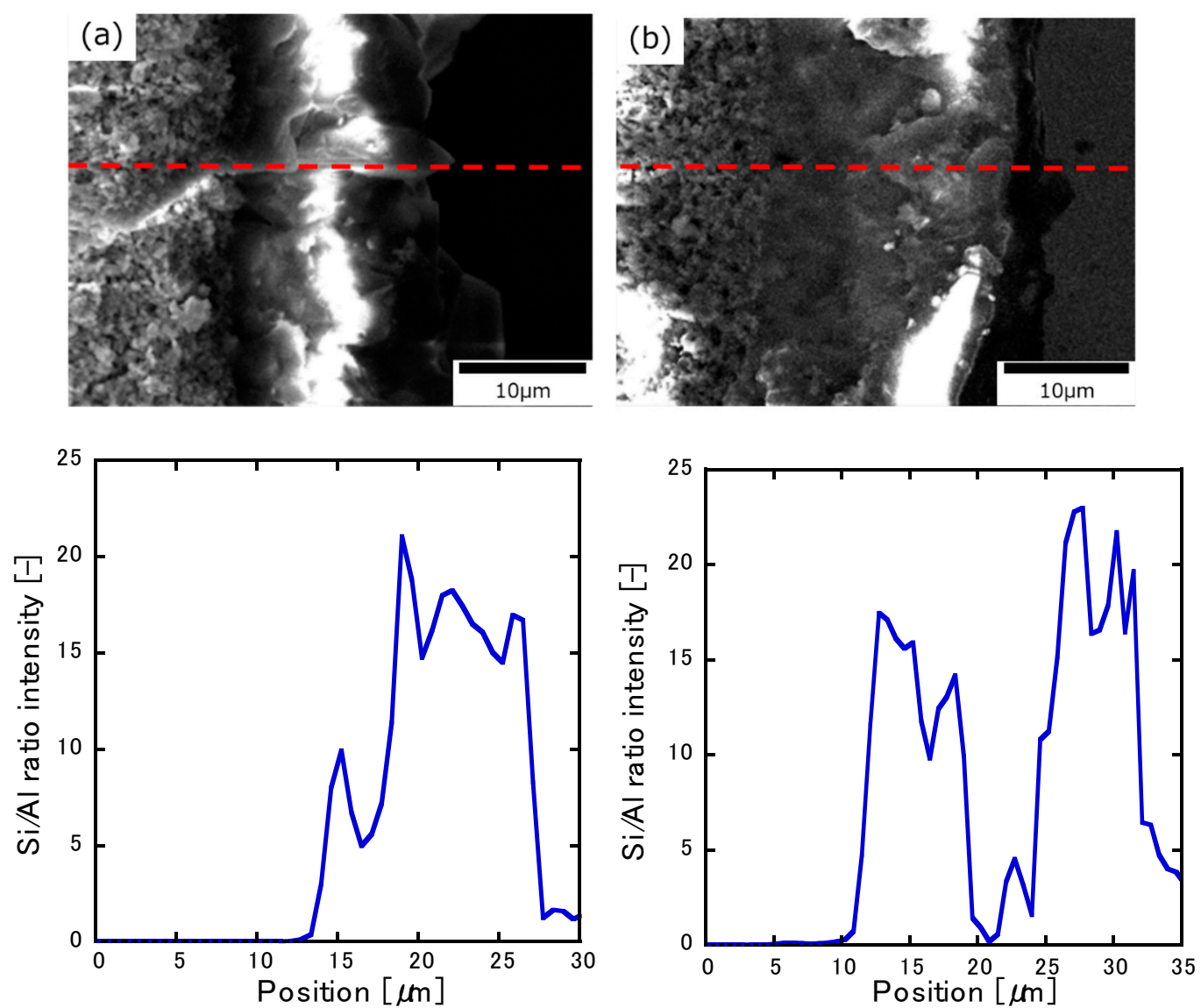

Figure 4. The cross-sectional view of the MFI-type zeolite membrane at (a) $\mathrm{Si} / \mathrm{Al}=25$ for the single-layer membrane and $(\mathbf{b})$ the two-layered membrane. The red lines indicate the locations where the line analysis was conducted. An average $\mathrm{Si} / \mathrm{Al}$ of $0.5 \mu \mathrm{m}$ was obtained.

\subsection{Gas Permeation Tests}

Next, the membrane's ability to facilitate gas permeation was evaluated using single-gas permeation tests. Here, the gas ratios of $\mathrm{H}_{2}, \mathrm{~N}_{2}$, and $\mathrm{SF}_{6}$, as well as the permeance ratio of $\mathrm{H}_{2} / \mathrm{SF}_{6}$, were determined (Figure 5). The gas molecular diameters were 0.29, 0.37, and $0.55 \mathrm{~nm}$, respectively, and the pore diameter of MFI-type zeolite was $0.55 \mathrm{~nm}$. Ideally, a membrane without cracks or pinholes 
should exhibit high $\mathrm{H}_{2}$ permeance and low $\mathrm{SF}_{6}$ permeance values; however, the membrane created in this study had a high $\mathrm{H}_{2} / \mathrm{SF}_{6}$ permeance ratio of between 150 and 450 , which meant that a dense membrane without any large defects was obtained. As shown, the $\mathrm{N}_{2}$ permeance was $1.1 \times 10^{-6}$ $\mathrm{mol} \cdot \mathrm{m}^{-2} \cdot \mathrm{s}^{-1} \cdot \mathrm{Pa}^{-1}$, which was reduced to $66 \%$ when compared with the previous report [11]. The inorganic gas permeability increased as a whole after the ion exchange process, and $\mathrm{H}_{2}$ permeability increased 1.5-fold from $1.1 \times 10^{-6}$ to $1.7 \times 10^{-6} \mathrm{~mol} \cdot \mathrm{m}^{-2} \cdot \mathrm{s}^{-1} \cdot \mathrm{Pa}^{-1}$. The permeability of $\mathrm{SF}_{6}$ increased about 5.5-fold from $5.5 \times 10^{-9}$ to $1.5 \times 10^{-8} \mathrm{~mol} \cdot \mathrm{m}^{-2} \cdot \mathrm{s}^{-1} \cdot \mathrm{Pa}^{-1}$. This was due to the gas diffusivity of the MFI pores, which changed because the $\mathrm{Na}^{+}$ions present in the MFI-type zeolite were replaced by $\mathrm{H}^{+}$. On the other hand, coating with silicalite- 1 reduced the $\mathrm{H}_{2}$ permeance by almost $70 \%$ (from $2.4 \times 10^{-6}$ to $7.5 \times 10^{-7} \mathrm{~mol} \cdot \mathrm{m}^{-2} \cdot \mathrm{s}^{-1} \cdot \mathrm{Pa}^{-1}$ ), whereas the $\mathrm{SF}_{6}$ permeance decreased by almost $50 \%$ (from $5.5 \times 10^{-9}$ to $\left.2.9 \times 10^{-9} \mathrm{~mol} \cdot \mathrm{m}^{-2} \cdot \mathrm{s}^{-1} \cdot \mathrm{Pa}^{-1}\right)$. Relative to the size of the molecule, the extent to which the $\mathrm{H}_{2}$ permeance decreased was quite large. This could be explained by the increase in the total thickness of the membrane due to the coating of the second layer. In the ion exchange process using the two-layered membrane, the $\mathrm{H}_{2}$ permeance changed from $7.4 \times 10^{-7}$ to $7.6 \times 10^{-7} \mathrm{~mol} \cdot \mathrm{m}^{-2} \cdot \mathrm{s}^{-1} \cdot \mathrm{Pa}^{-1}$, representing a relatively small difference. On the other hand, the permeability of $\mathrm{SF}_{6}$ increased 1.75 -fold from $2.9 \times 10^{-9}$ to $5.1 \times 10^{-9} \mathrm{~mol} \cdot \mathrm{m}^{-2} \cdot \mathrm{s}^{-1} \cdot \mathrm{Pa}^{-1}$. From this, the same trend as seen in the $\mathrm{Si} / \mathrm{Al}=25$ single-layer membrane was observed.

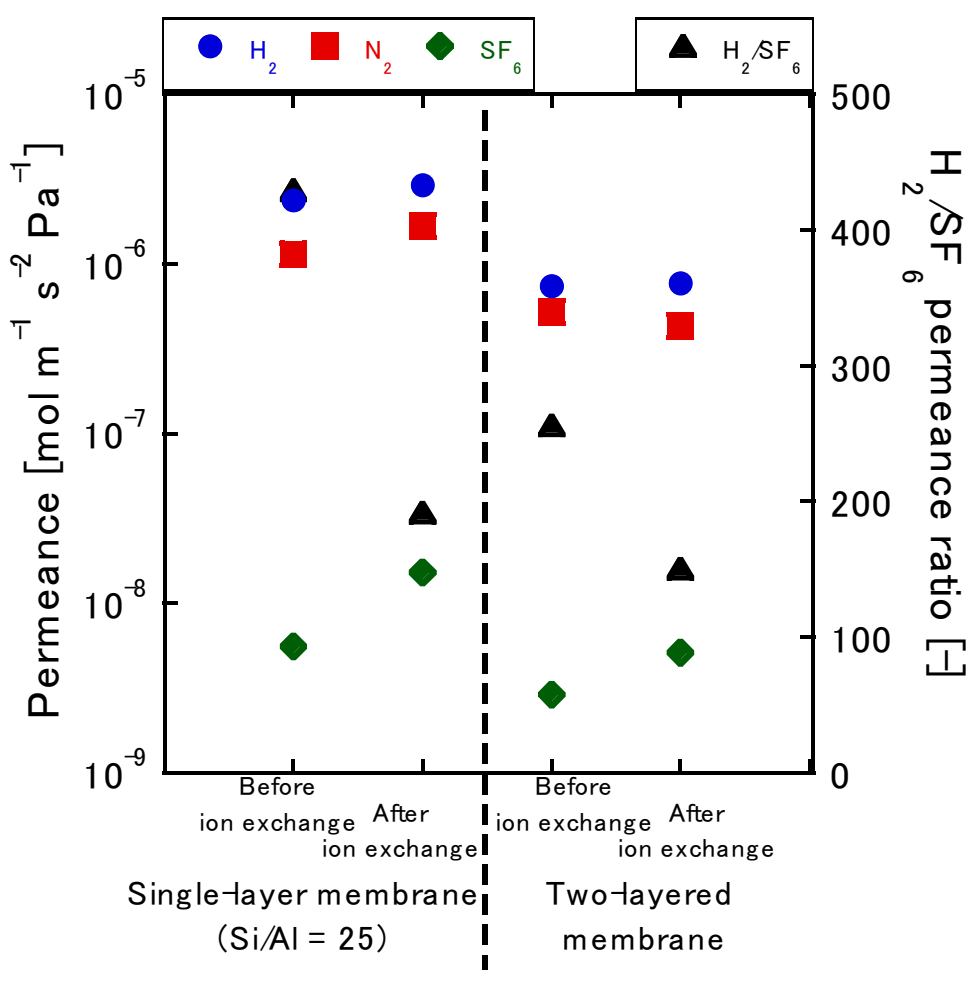

Figure 5. Single-gas permeance before and after ion exchange.

\subsection{MTO Reaction}

Figure 6 presents the initial conversion and selectivity of the MTO reaction tests for the single-layer and two-layered membranes. The $\mathrm{Si} / \mathrm{Al}$ ratios of the parent gel for the single-layer membrane were 25 and $\infty$. Here, the value obtained $15 \mathrm{~min}$ after the start of the reaction was defined as the initial conversion rate/selectivity. 


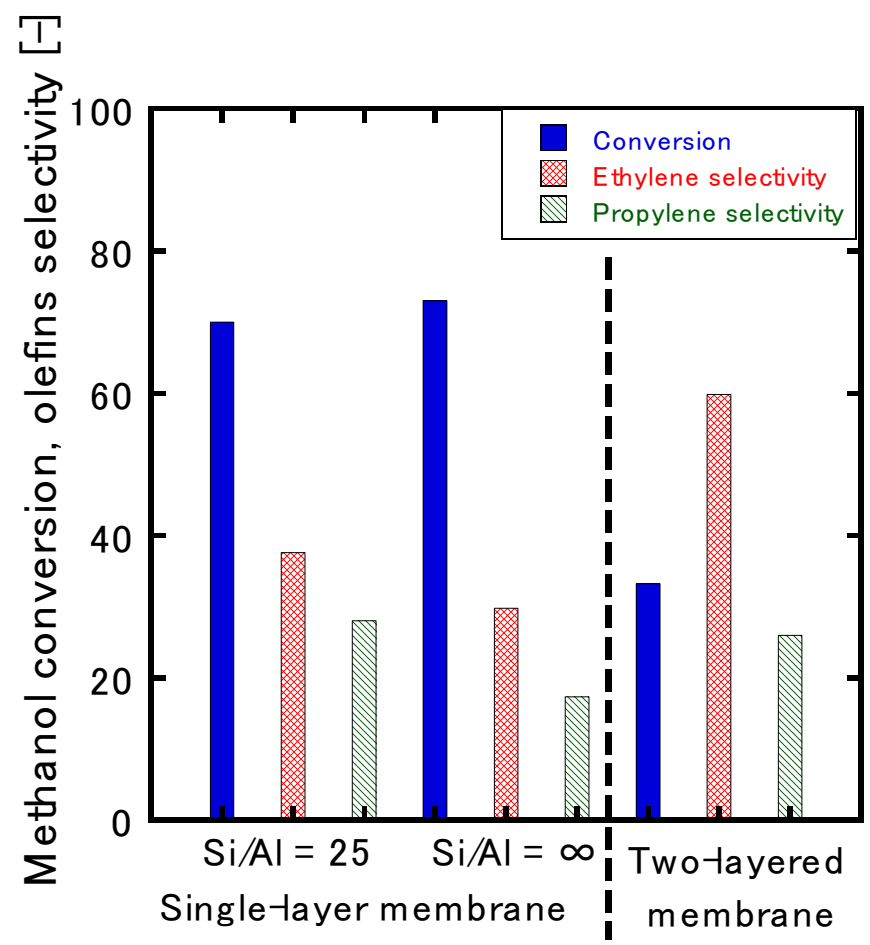

Figure 6. Effect of the $\mathrm{Si} / \mathrm{Al}$ ratio and the single- and two-layered membranes on the conversion rate and olefin selectivity.

When the ZSM-5 single-layer membrane was used, the conversion rate was 70\%, the ethylene selectivity was $38 \%$, and the propylene selectivity was $28 \%$. On the other hand, conversion on the two-layered membrane was $33 \%$, which was more than half of that observed for the ZSM- 5 single-layer membrane without any coating; however, the ethylene and propylene selectivity values were $60 \%$ and $25 \%$, respectively, and the overall selectivity for olefin was $85 \%$. It was theorized that this trend was due to the suppression of the reaction on the membrane's surface by the second layer. Therefore, it appeared that permeation of the membrane could be controlled by using the appropriate starting material. Figure 4 shows that $\mathrm{Al}$ was also introduced into the zeolite of the second layer; the reaction was expected to proceed without any notable influence on the selectivity. In this study, the reaction on the membrane's surface could be suppressed because the extent of crystallinity was insufficient (Figure 2), and there was the possibility that the Al detected by EDS was not contained within the zeolite framework. In addition, it can be observed from Figure 4 that the Si/Al intensity between 20 and $25 \mu \mathrm{m}$ was lower than that observed at another position because the concentration of the alkali during the synthesis of the second layer was high. However, it was not clear how this interface influenced the reaction. In a previous report [8], 90\% olefin selectivity was obtained by suppressing the reaction to paraffin and aromatic compounds that proceeded on the membrane's surface; thus, the reaction in this study could be similarly suppressed. Table 1 presents the O/P ratios of the ZSM- 5 single-layer and two-layered membranes. Here, the ratio of olefins to paraffins (hereafter referred to as the $\mathrm{O} / \mathrm{P}$ ratio) of the two-layered membrane increased from 13.1 to 26.6; this was further evidence that reaction suppression occurred.

Even though MTO reaction tests were conducted in this study using two types of membranes with different $\mathrm{Si} / \mathrm{Al}$ ratios, there was not much difference in the reactivity in relation to the $\mathrm{Al}$ content. With $\mathrm{Si} / \mathrm{Al}=25,70 \%$ olefin conversion, 38\% ethylene selectivity, and $28 \%$ propylene selectivity were obtained, whereas $73 \%$ olefin conversion, $28 \%$ ethylene selectivity, and $15 \%$ propylene selectivity were obtained when $\mathrm{Si} / \mathrm{Al}=\infty$. The reason for the conversion and olefin selectivity observed when $\mathrm{Si} / \mathrm{Al}=\infty$ could be that the $\mathrm{Al}$ concentration in the MFI-type zeolite layer remained at the same level due to the elution of $\mathrm{Al}$ from the alumina substrate (Figure 4). In addition, the deactivation of the catalyst was 
very fast, regardless of the amount of $\mathrm{Al}$; within $60 \mathrm{~min}$ of the start of the reaction, reactivity dropped sharply from an olefin conversion rate of $70 \%$ to $59 \%$, and selectivity dropped from $65 \%$ to $7 \%$. Most notable was the fact that, after the reaction, the membrane was entirely black due to the deactivation of the catalyst via coke deposition.

Table 1. Comparison of the olefin:paraffin ratio $(\mathrm{O} / \mathrm{P}$ ratio) of the products.

\begin{tabular}{ccc}
\hline Name & Experimental Method & O/P Ratio (-) \\
\hline Single-layer membrane $(\mathrm{Si} / \mathrm{Al}=25)$ & Cross-flow & 13.1 \\
\hline Previous study [7] & Dead-end & 3.5 \\
\hline Two-layered membrane & Cross-flow & 26.6 \\
\hline
\end{tabular}

In addition, both the conversion rate and the selectivity were about $20 \%$ lower than the values reported in the previous studies; this was attributed to differences in the test methods. In this study, the reaction was carried out via the cross-flow method, whereas the dead-end method was used in previous studies [7]. In the cross-flow method, $\mathrm{MeOH}$ molecules permeated the membrane due to a partial pressure difference, and all the $\mathrm{MeOH}$ molecules that did not permeate the membrane flowed to the vent side. On the other hand, $\mathrm{MeOH}$ molecules in the dead-end method permeated the membrane via a pressure difference between the outside and inside of the membrane, and all the MeOH molecules that were outside of the membrane also permeated the inside of the membrane. In the current study, the vapor pressure of $\mathrm{MeOH}$ was $28 \mathrm{kPa}$, whereas the previous study reported a value of $0.67 \mathrm{kPa}$, which was $1 / 20$ of the value observed in the current study. The reaction times for both methodologies are notably different. In the dead-end method, the pressure was low because the reactants tended to stay within the zeolite layer, thereby extending their contact time with the catalyst. On the other hand, the pressure tended to be high in the cross-flow method because permeation of the zeolite layer was a fast process, and the $\mathrm{MeOH}$ molecules did not readily react. Thus, while a higher conversion rate was obtained in the previously reported experiment using the dead-end method, the cross-flow method had the advantage of being more selective toward the generation of olefin. In Table 1, the ratios of products derived from the carbon number of olefins and paraffins (the O/P ratio) are summarized. Generally, the values observed in the previous studies approximated the results observed on the membrane permeation side. When comparing the two, an O/P ratio of 13.1 was obtained in the current study, which was 3.5-fold greater than that (an O/P ratio of 3.5) observed in the previous report. This was clear evidence that the cross-flow method was preferentially selective toward the generation of olefin.

\subsection{Catalyst Regeneration}

Figure 7 presents a plot of the course of the reaction's time against the conversion and selectivity of the MTO reaction in the ZSM-5-type single-layer membrane. The conversion rate and selectivity both peaked at $15 \mathrm{~min}$ and then experienced a rapid decrease. Almost no olefin was obtained 240 min after the start of the reaction, and the ethylene selectivity was only $4 \%$, which resulted in a large amount of DME. Propylene was not observed after $15 \mathrm{~min}$, which indicated that the catalyst was deactivated by the formation of coke on the membrane surface. This deactivation issue was, however, resolved upon treatment with $\mathrm{O}_{3}$ (Figure 8). 


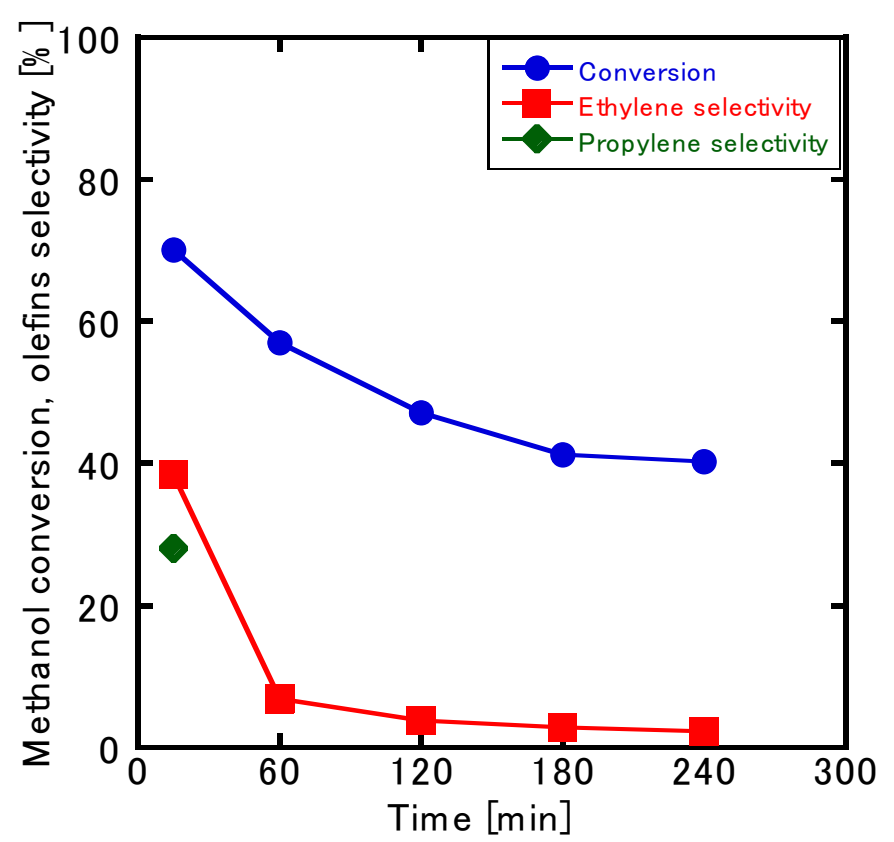

Figure 7. Changes in the conversion and selectivity over the course of the $\mathrm{MTO}$ reaction in an $\mathrm{Si} / \mathrm{Al}=$ 25 membrane.

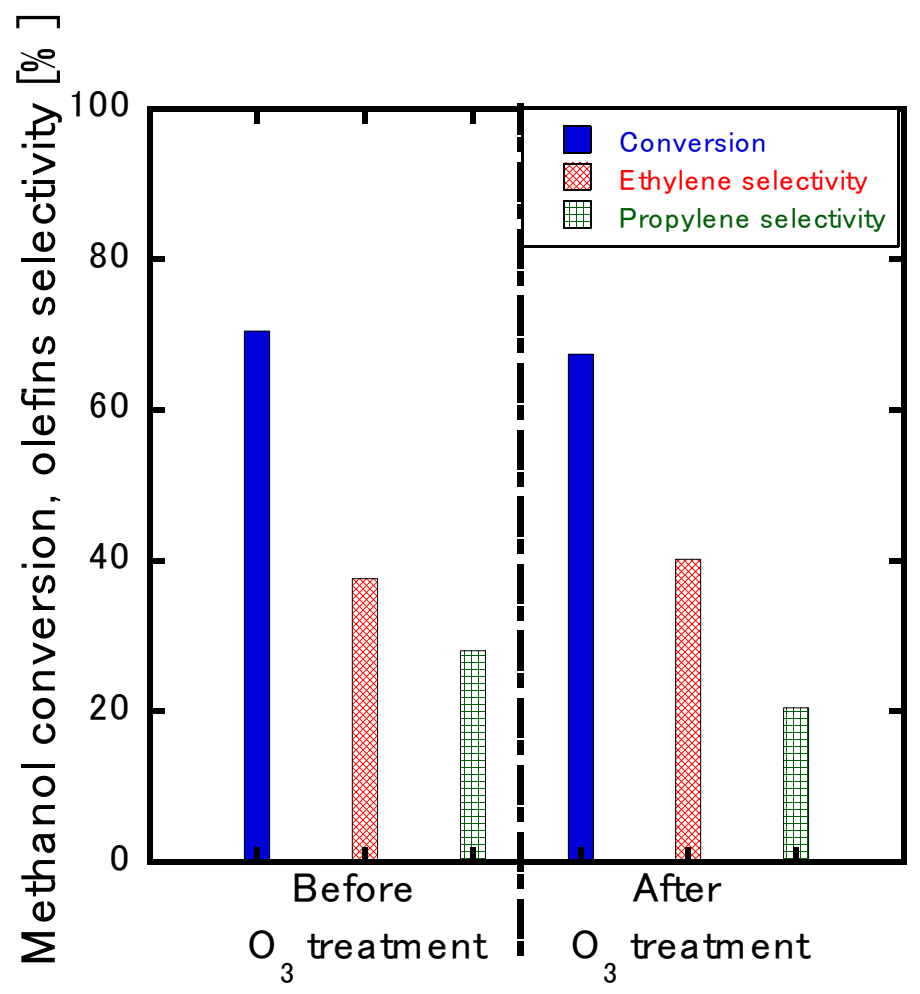

Figure 8. Comparison of the initial conversion rate and selectivity before and after $\mathrm{O}_{3}$ treatment.

The ozone-treated membrane exhibited $67 \%$ methanol conversion, $40 \%$ ethylene selectivity, and $25 \%$ propylene selectivity. When the results before and after ozone treatment were compared, the conversion rate and selectivity decreased slightly by about $2 \%$ to $5 \%$. This was the result of the removal of coke via oxidation into carbon dioxide. In a previous report [12], the membrane was blackened before the $\mathrm{O}_{3}$ treatment was performed; however, the film turned white upon treatment 
with $\mathrm{O}_{3}$. In addition, the MFI-type zeolite crystal was not destroyed during the treatment process because the film's performance and the XRD patterns exhibited no deterioration after $\mathrm{O}_{3}$ treatment.

Figure 9 presents a plot of the changes in the conversion rate and reaction selectivity against time before and after $\mathrm{O}_{3}$ treatment. Here, it can be observed that, although the catalyst's performance was temporarily recovered by the $\mathrm{O}_{3}$ treatment process, both the conversion rate and the selectivity decreased just as rapidly as before $\mathrm{O}_{3}$ treatment. In particular, the rate of reduction for the conversion value observed at the 60 -min mark was large; about $57 \%$ was obtained before $\mathrm{O}_{3}$ treatment, but only about $45 \%$ was noted after treatment. It is possible that the regeneration of the catalyst by $\mathrm{O}_{3}$ treatment was inadequate; thus, finding more effective means of prolonging the catalyst's performance should be a principal goal for the future development of contactor-type membrane reactors.

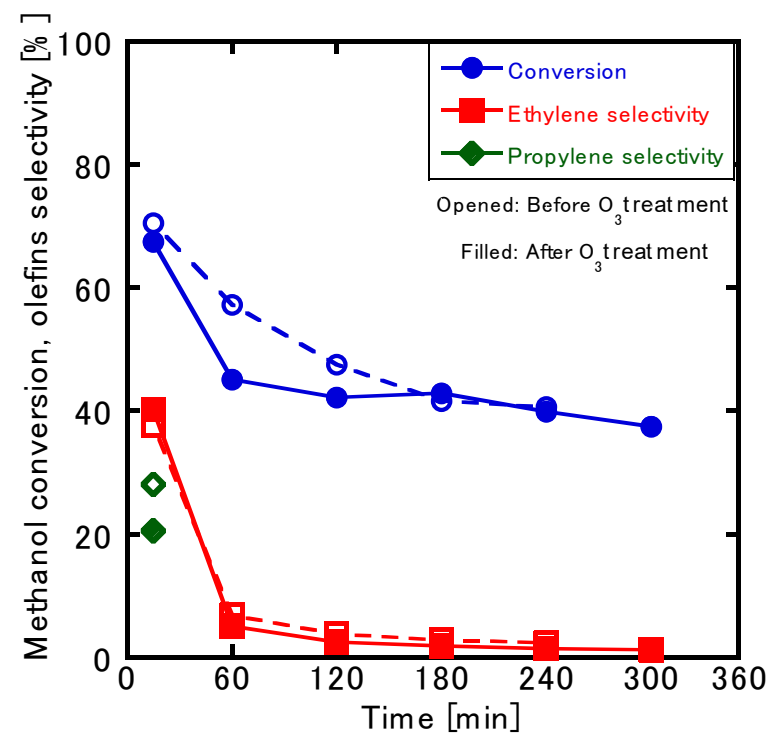

Figure 9. Comparison of the conversion and selectivity rates before and after $\mathrm{O}_{3}$ treatment.

\section{Conclusions}

An MFI-type zeolite membrane contactor that was synthesized using the cross-flow method was shown to be effective for MTO reactions. Here, methanol conversion was $70 \%$ with $38 \%$ ethylene selectivity and $28 \%$ propylene selectivity when the MFI-type zeolite membrane had an $\mathrm{Si} / \mathrm{Al}$ ratio of 25. By applying the coating of the MFI -type zeolite layer without $\mathrm{Al}$, the ethylene selectivity and propylene selectivity were improved to $60 \%$ and $25 \%$, respectively, and the total olefin selectivity also increased to $85 \%$. This was attributed to the suppression of the surface reaction by the MFI-type zeolite layer coating. The catalytic activity for the MFI-type zeolite membrane contactor could be regenerated by treatment with $\mathrm{O}_{3}$.

Author Contributions: The experimental work was designed and carried out by T.Y. and K.I. under the guidance of M.N. The manuscript was written by S.T. and reviewed by all authors. All authors approved the final version of the manuscript.

Funding: This research received no external funding.

Acknowledgments: The authors would like to thank Enago (www.enago.jp) for the English language review.

Conflicts of Interest: The authors declare no conflict of interest.

\section{References}

1. Zhong, J.; Han, J.; Wei, Y.; Xu, S.; Sun, T.; Guo, X.; Song, C.; Liu, Z. The template-assisted zinc ion incorporation in SAPO-34 and the enhanced ethylene selectivity in MTO reaction. J. Energy Chem. 2019, 32, 174-181. [CrossRef] 
2. Olsbye, U.; Svelle, S.; Bjorgen, M.; Beato, P.; Janssens, T.; Joensen, F.; Bordiga, S.; Lillerud, K. Conversion of Methanol to Hydrocarbons: How Zeolite Cavity and Pore Size Controls Product Selectivity. Angew. Chem. Int. Ed. 2012, 51, 5810-5831. [CrossRef] [PubMed]

3. Aghaei, E.; Haghighi, M. Hydrothermal synthesis of nanostructured Ce-SAPO-34: High-performance and long-lifetime catalyst with various ceria contents for methanol to light olefins conversion. Microporous Mesoporous Mater. 2018, 270, 227-240. [CrossRef]

4. Dyballa, M.; Obenaus, U.; Blum, M.; Dai, W. Alkali metal ion exchanged ZSM-5 catalyst: On acidity and methanol-to-olefin performance. Catal. Sci. Technol. 2018, 8, 4440-4449. [CrossRef]

5. Rostamizadeh, M.; Yaripour, F.; Hazrati, H. High efficient mesoporous HZSM-5 nanocatalyst development through desilication with mixed alkaline solution for methanol to olefin reaction. J. Porous Mater. 2018, 25, 1287-1299. [CrossRef]

6. Wang, F.; Chu, X.; Zhu, F.; Li, Q.; Liu, B.; Xiao, G. Producing BTX aromatics-enriched oil from biomass derived glycerol using dealuminated HZSM-5 by successive steaming and acid leaching as catalyst: Reactivity, acidity and product distribution. Microporous Mesoporous Mater. 2019, 277, 289-294. [CrossRef]

7. Masuda, T.; Asanuma, T.; Shouji, M.; Kawase, M.; Hashimoto, K. Methanol to olefins using ZSM-5 zeolite catalyst membrane reactor. Chem. Eng. Sci. 2003, 58, 649-656. [CrossRef]

8. Tago, T.; Iwakai, K.; Morita, K.; Tanaka, K.; Masuda, T. Control of acid-site location of ZSM-5 zeolite membrane and its application to the MTO reaction. Catal. Today 2005, 105, 662-666. [CrossRef]

9. Sugiyama, Y.; Ikarugi, S.; Oura, K.; Ikeda, A.; Matsuyama, E.; Ono, R.; Nomura, M.; Tawarayama, H.; Saito, T.; Kuwahara, K. MFI zeolite membranes prepared on novel silica substrates. J. Chem. Eng. Jpn. 2015, 48, 891-896. [CrossRef]

10. Ueno, K.; Negishi, H.; Miyamoto, M.; Uemiya, S.; Oumi, Y. Effect of deposition seed crystal amount on the $\alpha-\mathrm{Al}_{2} \mathrm{O}_{3}$ support and separation performance of silicalite- 1 membranes for acetic acid/water mixture. Sep. Purif. Technol. 2010, 174, 57-65. [CrossRef]

11. Zhou, M.; Chen, X.; Kita, H. Inexpensive synthesis of silicalite-1 membranes with high pervaporation performance. Chem. Lett. 2010, 39, 388-389. [CrossRef]

12. Khanghham, S.; Julcour, C.; Damronglerd, S.; Ngamcharussrivichai, C.; Manero, M.; Delmas, H. Regeneration of coked zeolite from PMMA cracking process by ozonation. Appl. Catal. B 2013, 140-141, 396-405. [CrossRef] 